\title{
Transition Programs Available For Students with Intellectual Disability towards Community Integration in Ghana
}

\author{
Yaw Frimpong, Obeng Kwakye \\ Department of Public Policy and Management, Jiangsu University, China
}

\begin{abstract}
Students with intellectual disabilities have very low IQ and low reasoning abilities which makes them unable to live independent lives. This makes it very necessary for special schools across the country to offer transitional programs to enable these individuals acquire the requisite skills that would empower them to integrate into their various communities. It is in the light of this that this research was conducted to examine the transitional programs available for students with intellectual disability and to establish how the transition programs prepared them for community integration in Ghana
\end{abstract}

Piaget's theory was adopted by the researcher. This theory deals with the nature of knowledge itself and how people acquire, construct, and use it. The design for this study was descriptive and the approach adopted was qualitative which involved the use of semi-structured interviews in the collection of data. Purposive sampling technique was used to select the teachers, and house mothers, while a simple random sampling technique was used to select the parents/guardians.

The findings of the study indicated generally that transition programs available in the special schools are not given much attention and such programs are not well structured to meet the needs of the students due to lack of inadequate teaching and learning resources. Besides this major finding, the study also revealed setbacks such as lack of governmental support in the area of policy and grants that have affected the progression of the program since the needs of individuals with intellectual disability are not adequately met.

In conclusion, it is recommended that the government through the Ministry of Education and teachers should pay more attention to the available programs for these students with intellectual disabilities to enable them transit from school to work with ease.

Key words: transition, intellectual disability, programs, community integration.

\section{INTRODUCTION}

$\mathrm{P}$ eople with intellectual disabilities are generally characterized by below-average mental functioning and concomitant limitations that can be observed in two or more adaptive skills: conceptual skills, social skills, and practical skills (American Association for Intellectual and Developmental Disabilities - AAIDD, 2010). The World Health Organization (WHO, 2015) added that Intellectual Disability (ID) is described as a significant reduction in the ability to understand, recognize, and apply a variety of complex information or skills, leading to an individual's inability to live an independent life and the condition started before adulthood which has a long-term impact on development. Under-intellectual functioning, coupled with one or more restrictions on the abovementioned adaptive skills of persons with intellectual disabilities, particularly students with intellectual disabilities, indicates the need for transition programs in special schools to help them integrate and remain independent in their various communities.

Avoke et al. (1998), cited in (Mantey 2017) states that various transition programs have already been in existence in Ghana since the era of the Castle schools, the missionaries introduced vocational trades in the elementary, secondary and tertiary schools, although emphasis later shifted to literacy. Among the trades or training that were introduced to the children who enrolled in the castle schools were farming, masonry, blacksmithing, and carpentry. These enabled individuals to be well equipped with skills after school. It is an undeniable fact that preparation for life after school is of paramount importance. How then can we include students with or without disabilities particularly those with Intellectual Disability fully and at the same time prepare them for life after school?

Ultimately, the goals for their education are to enable them to obtain gainful employment, transit to post-secondary programs and become contributors to the nation as in the capacity of good citizens. (Avoke et al 2004). In addressing the needs of students with disabilities with particular reference to Intellectual Disability within this construct, it is important to take cognizant of the fact that vocational education is paramount for independent living as part of their transition services into their various communities.

The author further explains that in recent years, the curriculum used in most schools in Ghana has placed major emphasis on the acquisitions of vocational skills. Thus forming the integral component of secondary education. Individuals whether disabled or not are required to be offered with structured and intensive vocational training to enable them equipped with functional skills to lead productive lives in their various communities after training.

This, however, has been the source of difficult particularly for students with intellectual disabilities as well as the other 
disabilities in Ghana. A number of rehabilitation centers and special schools with particular reference to Community Special Vocational School have been set up to address this problem, yet rehabilitation centers for the disabled in itself do not solve the problem completely.

Clark and Kolstoe (2014) as cited by (Ametepee and Anastasiou 2015) observed that programs offered in these special schools and centers do not sufficiently meet a number of their educational and training needs. This notwithstanding, (Abdullah, Cudjoe, et al. 2018) added that these programs, however, limit the range of occupations for which individuals with disabilities are prepared for complete community integration. Besides, most individuals still perpetuate the notion that being intellectually disabled means the individual is different, bringing about discrimination and labeling on the individual. This usually appears that such individuals placed in these centers' do not get the adequate support and attention needed. (Crosbie and O'Sullivan 2015)

Another variable contributing factor is the ineffectiveness of transitional programs relating to the over-reliance on the traditional work-study approach in the preparation of individuals with disabilities particularly the intellectual disabled. Wood, (1993), as cited in (Olusanya, Davis et al. 2018) added that although the work-study program is valuable in a certain environment, such programs severely restrict the range of available career options in a competitive market.

In this radically challenged environment, what are now the prospects for students with disabilities on leaving school or training programs?

Boyle et.al (2018) pinpoints the above solution on the need for trans-disciplinary approach to preparation of individuals with disabilities for smooth and successful community participation hence, the need for effective transition programs to address the specific needs of individuals particularly those with intellectual disabilities as they move from one developmental phase to another, in this instance from a student to a worker or adolescence to adulthood. The author, however, defines transitions as a carefully planned process, which may be initiated by either school personnel or adult services provider, to establish and employ a plan for either employment or additional vocational training of a student with disabilities who will graduate or leave school in 3-5 years.

In other words IDEA '97 also defines transition programming as a coordinated set of activities for a student with disabilities, designed with an outcome-oriented process that promotes movement from school to post-secondary, education vocational training, integrated competitive employment for community participation some of these activities include occupational training programs, information on the awareness of job opportunities, characteristics of job and workers requisites skills and expectations. These programs have been categorized under four domains which are model into vocational, community, leisure and domestic. (Welhman 1996; Przybylowicz 2018)
Contrary to what has been defined by the authors, it is a contributing factor that brings about the ineffectiveness of transition programs relative to the over-reliance on the traditional work-study approach in their preparation. Due to the competitive nature of career available, individuals with intellectual disabilities have no option, than to stick to the already known methods and traditional way of skills training. In this radically challenged environment, most of the special or vocational and rehabilitation training centers rely on only two or three kinds of training such as basketry, leatherwork, and beads making. These programs offered in these centers and schools do not sufficiently meet a number of their educational and vocational needs. Nevertheless, limiting, the range of occupations for these individuals with intellectual disabilities for complete community integration.

\subsection{Problem Statement}

Although the syllabus for special schools for students with intellectual disabilities in Ghana describes some of the transitional programs needed to improve the independent living and community integration of students with developmental disabilities, the students who have attended such programs do not appear to prepare to meet the demands of life after school. The researcher noted that many former special school students are unable to demonstrate the skills they had acquired in schools.

\section{Objective}

The current study aimed to examine the transitioning programs for students with disabilities particularly those with intellectual disabilities at Deduako Community Special Vocational School and Garden City Special School towards community integration, and determine the ways transition programs prepare the students for community integration. To end this, the research focused on the resources that are available for effective transition programming in the selected schools.

\section{MATERIALS AND METHOD}

The paper adopted a qualitative approach and descriptive exploratory design on transition programs available for students with intellectual disability in the Deduako Community and Garden City special schools, and explored the challenges that affect the effectiveness of transition programs in the selected schools.

The study relied on in-depth semi structured interviews with surveys of experiences of teachers, house mothers and parents of the students, and grounded theory was used to reveal common themes derived from the data itself (Glaser \& Strauss, 1967). The grounded theory operates virtually in a reverse fashion from traditional social science analysis. The primary step for the grounded theory is to collect information through a spread of methods. The key points are marked with a series of codes extracted from the information collected. Then, the codes are classified into similar ideas and categories are formed from these ideas. Grounded theory, that has been a 
classic and still standard technique for analyzing health information and aims to conceptualize what is happening by using empirical research, is useful to explain the similarities among persons with particular experience

\subsection{The Study Setting}

The study was carried out in two special schools in the metropolitan area of Kumasi - Community Vocational Special School and Garden City Special School. These schools provide vocational training for children or individuals belonging to one of the levels or ranges of intellectual disabilities (mild, moderate, severe and profound). More specifically, the dominant groups of intellectual disabilities that were identified in both settings were people with Down syndrome, autism spectrum disorder, dyslexia, fragile $\mathrm{X}$ syndrome, and hyperactivity disorder with a deficit of attention (ADHD). Schools are committed to providing training and education to children with developmental disabilities to enable them to acquire basic life, functional motor skills, gross motor skills, and fine motor skills

\subsection{Population and Sample}

The target population was made up of teachers and house mothers who had worked in the selected special schools for a period of two years and more, as well as parents who had enrolled their children with intellectual disability in the two selected schools. House mothers are women who work in the special school selected as helpers and assist students in activities of daily living. In all, there were 31 participants: 13 teachers, 9 mothers, and 9 parents

The purposive sampling technique was employed in selecting the respondents from the special schools. This sampling method enabled the researcher to select only those who are conversant on the topic under study and can provide useful information.

A simple random sampling technique was used to select parents whose children were enrolled in selected schools. Researchers visited these schools during the day of the ParentTeacher Association (PTA) meeting to interview parents. Each presentation of the parents was given a paper on which they could write their full name. These papers were folded and placed in a bowl, shook, and then one of the researchers randomly selected 9 names (from two selected schools).

\subsection{Data Collection and Instrument}

Face-to-face interviews were held with two groups of participants, teachers, and housemothers, in the study area. Individuals present during a single interview was included one participant and the researcher (interviewer) to take notes. A voice recorder was used during the discussions. Each interview lasted approximately 50 minutes. In-depth interviews were conducted using an interview guide to collect data from the participants. This allowed the researcher to quote directly from the participants and to provide a fluent speech flow using their local dialect. While the interviews were conducted in English for teachers, Twi language was used to interview parents as well as the house mothers.

The interview guide was in two sections. The first section specifically sought demographic data of respondents: age, gender, number of years teaching, and educational qualification. In section two, the items sought information on 'transition programs available for students with intellectual disability, how these programs prepare the students for community integration and so on'.

\subsection{Data Analysis}

The audio-recordings in English were transcribed verbatim by the researchers, while the recordings in the Twi Language were given to experts of Modern Languages, to be converted to English transcripts. For accuracy, the transcriptions were compared again with the notes the research assistant took during the interviews at the study sites. All the transcripts were then given to two coders who had been trained for grounded theory and opening coding independently coded the translations for themes, subthemes, and categories. Open coding that is conceptualizing on the first level of abstraction (Strauss \& Corbin, 1997) was conducted by two coders with line by- line coding. The codes were checked by the first author to ensure the validity of the interview coding. Discrepancies in coding were resolved by discussion among the coders. After the consensus of the codes was obtained, the codes were put into categories, from which the themes and subthemes were extracted. Extra readers were invited to help resolve any differences between the researchers' summaries.

\section{RESULTS}

\subsection{Demographics of Respondents}

Table 1 Demographic Characteristics of the Respondents

\begin{tabular}{|c|c|c|}
\hline \multicolumn{3}{|c|}{ Status of Respondents } \\
\hline \multicolumn{2}{|c|}{$\begin{array}{c}\text { Frequency } \\
(\mathrm{N}=31)\end{array}$} & $\begin{array}{c}\text { Percentage } \\
(\%)\end{array}$ \\
\hline Teachers & 13 & 42 \\
\hline House Mothers & 9 & 29 \\
\hline Parents & 9 & 29 \\
\hline Total & 31 & 100 \\
\hline Males & 11 & 35 \\
\hline Females & 20 & 65 \\
\hline Total & 31 & 100 \\
\hline \multicolumn{3}{|c|}{ Age Group } \\
\hline 30-39 years & 13 & 42 \\
\hline $40-49$ years & 11 & 35 \\
\hline $50-59$ years & 7 & 23 \\
\hline Total & 31 & 100 \\
\hline
\end{tabular}




\begin{tabular}{|c|c|c|}
\hline \multicolumn{3}{|c|}{ Educational Qualification } \\
\hline Middle school Leavers & 7 & 22 \\
\hline Senior High School & 8 & 26 \\
\hline Tertiary & 16 & 52 \\
\hline Total & 31 & 100 \\
\hline \multicolumn{2}{|c|}{ Work Experience } \\
\hline 3-5 years & 9 & 29 \\
\hline 6 years and above & 22 & 71 \\
\hline Total & 31 & 100 \\
\hline
\end{tabular}

The findings revealed that the majority of the participants were below the age of 50 years. In terms of education, it was found that most of them had obtained their first and second degrees (undergraduate and postgraduate) (the teachers and parents), while a few had studied up to middle school (the house mothers). More females' represent $65 \%$ took part in the study than males, partly because the house mothers were all females. Again, the results indicated that the majority of the teachers and housemothers had worked in the selected schools for a period of 6 years and more.

\subsection{Availability of Transition Programs for Students with Intellectual Disability in the Schools}

\subsubsection{Programs offered in the schools}

The teachers remarked that they undertake both academic programs such as arithmetic and mathematics, language literacy, and skills in home management, daily living skills, and pre-vocational skills. Additionally, vocational programs such as leatherwork, chalking making, candle making, doormat, tie and dye, art and painting, beads making, etc. are offered in both schools. Emphasis were made by some of the teachers on the need for students to be independent after the transition, they needed to go through these skills thoroughly in order to grasp the concept very well. It was observed that other professionals such as the counselors that take them through a psychological build-up to prepare them towards adjusting themselves in their community after training. However, an analysis of data revealed that programs offered at the special schools did not meet the needs of the students; for instance, in the area of vocational programs which forms part of their preparation, according to the staff is "nothing to write home about" as commented by them. The workshops available at both schools are not resourceful enough to cater for the needs of individuals with intellectual disability, hence they were forced to undertake any vocation contrary to their interest. The comments below depict the views of the respondents concerning programs available in both schools;

“...Yes, though instead, of undertaking the programs of their choice, their hands were tied to only a handful of them such as candle making, chalk making, arts, and craft. However, materials used in making some of these products could be unavailable for a long time due to inadequate funds".

"...Materials used in making some of these products could be unavailable for a long time due to inadequate funds and would have to switch to a different one in which raw materials are gotten locally. Some could be attributed to the lack of tools and equipment to carry out the work successfully".

"...Some could be attributed to the lack of tools and equipment to carry out the work successfully"

Contrary to these problems a parent also supports the idea of quality availability of programs and added that to him the programs are very good.

\section{"...Now my son is very responsible when he comes on vacation from school; he does his own washing of clothes and good at painting. In fact, I don't regret sending him to the school"}

On this issue, most of the teachers emphasized that some of the programs offered do not have bearings to the needs of the students, as a result of lack of proper coordination and structures in place to facilitate the effectiveness of transitioning the individuals into the community after training.

As a consequence of these experiences, most of these individuals cannot graduate and those fortunate ones also lack the basic skills needed to function in their adult lives

\subsubsection{Benefits of programs}

The study revealed that the programs stated earlier have adversely affected the lives of the children positively and one of the respondents said that, he can boast of a student who is now working with one of the best shoemakers in town. In other instances, there are other ones who are also good at candle and beads making, however, due to the perception people have about these students do not patronize their services. On the other hand, there are problems such as inadequacy of resources such as material, financial and human, available spacious classrooms for conducive learning, tools, and equipment.

Indeed, these problems were acknowledged to be a contributing factor to the influence of an individual's welfare for successful community integration as commented by the respondents as follows;
“...I don't even know what will become of my son after his training in the school? This is because I can't really figure out what he can do better after being at the special school for about six years". "...We do not have any mechanism to evaluate student's performances. There is no follow up on those who have since been out".

\subsubsection{Structure of programs to meet the needs of the students}


For effective transition programming, the needs of the people are essential for their community integration. Considering, the content in their syllabus, the teachers commented that, it's categorically into two sections: the academic and the vocational aspect geared towards the effective training of these students. At the special schools, individuals are assessed on their functionality and capabilities, the strength and weakness to make sure they are ready to meet the demands of work. It could be stated that most of their work is usually more academic than the practical due to the fact that there are inadequate resources at both schools. Below are some comments made by others?

\section{"...There is no policy supporting transition programming as the other programs do”.}

“...The structure of transition programs can be described as porous with no effective guidelines used as directives for teaching”.

“...There are no specific structures in place from evaluation, follow-ups, lack of coordination and linkages of all special schools available across the country. What annoys me most is the absence of inservice training for us, the teachers".

\subsection{How Transition Programs Prepare the Students for} Community Integration

There is no doubt that most people with disabilities, especially, the intellectually disabled spent most of their time in special schools. This, notwithstanding is a no different issue with those in Deduako Vocational Special School and Garden City Special School, where these individuals undergo various kinds of training in order to adjust themselves in their community after their training programs. It is evident in Ghana, that, the ultimate aim of training these individuals is to equip them with function-able skills to enable them to live independent lives. However, the majority of these individuals according to Avoke (1998) become a burden unto their families due to the nature of the training they undergo. When asked about the functionality of the training programs for the intellectually disabled at Deduako Vocational Center, the staff had the following statement given:

\subsubsection{Functionality of programs to students}

On how programs are function able to students, some of the respondents indicated that;

"...Adopting the general curriculum has limited the standard of achieving the target set for the prevailing programs run in the school. We do our best to make the programs fit the needs of these students, however, most of the training methods are outmoded and do not seem to go with the modern trend of technology”.

“...There is no specialist to take the students through the modern trends of training and no guidance. No right set of equipment and tools for the various craftworks. We are restricted".
"...We hardly have in-service training to upgrade ourselves. It was also revealed that for the past five years passed students from the respective schools are in the community working and are doing well at their various workplaces".

\subsubsection{Conducive nature of environment for students}

Community integration is all about students with intellectual disabilities learning alongside people in their local neighborhood, participating in normal activities, thus reducing the fears about their social environment. The views of the teachers, house mothers and parents revealed that the atmosphere in the school is welcoming and makes it conducive for learning. Their diverse responses are as follows:

"...There are mothers who take care of their washing, eating, and upkeep of the body and are motivated through the playing of games as well as sightseeing around the community"

"...Although, the staff is not adequately enough, those present also treat the students as their own, however, there are a few bad nuts who have no patience and tend to mistreat the children anyhow".

One teacher said; "tools are not enough but I encourage them to use what is available through demonstration”.

“...I don't want my son to come home because he has a lot of chances to play on a large compound. I am a house mother who takes care of about twenty - one (21) children. I teach them about personal hygiene, body grooming especially the females. How to care for themselves during their menstrual period"

"...In order to encourage them, we sometimes go for sight-seeing around the neighborhood to see and feel what is happening around them. As a sports teacher, I organize fun games such as football, eating completion, tug-of-peace between the boys and girls".

The study also revealed that students are not forced to work or decision being made on behave of them even though they are guided by their teachers and housemothers; they are allowed to make their own decisions

\subsubsection{Assessment on student's performance}

The reality at present is that most special schools do not have mechanisms for the evaluation of their students' performances. This is a no different issue for those at Deduako Vocational special school and Garden City Special School; as some of the teachers remarked that there are no formalized structures of assessments; however, the students are allowed to work alone with a little close supervision and guidance occasional. This way, their work done is used for evaluation of their performance. 
Their views were supported by one house mother who added that; there are no criteria to which they assess the children but once a while, they are made to practice what they have learned so far alone. They sometimes work in groups on a different task in a form of competition to boost their morale for working hard.

\subsection{4: Support from Community members to the school}

According to Landesman Ramey and Ramey (1999), special schools and rehabilitation centers have had a varying history of involvement with their local communities. It is crucial to establish the nature of community contacts and access to community facilities that were available to their children. From the research, there is some evidence that the local community supported the center and the relationship existing between the school and the community is generally cordial.

"...The communities come to weed around the place when the place is grown with weeds and occasionally donate some items to the school".

"...Recently, we had our showcase of some of their work on display for the community members to come and appreciate their work and turnout was very great".

“...We occasionally receive a donation from some of the wells to do members in the community”.

\subsubsection{Relationship between protocol and management}

On the issue concerning the relationship existing between protocol and management; relatively, it can be said that the relationship between the staff and management is also cordial and they share a vision, working towards achieving that.

“...More often we have meetings to deliberate on issues concerning the welfare of us, the staff and pupils. In our last staff meeting, we were asked to write our concerns bothering our minds. I can say the relationship is very good. Decisions are not imposed on us; we all agree to disagree and come to a common consensus".

\subsection{Resources Available for Effective Transition Programming in the Schools}

\subsubsection{Structure of curriculum to meet the students' needs}

Statement from the teachers show that there are resources that include human, material and structure-wise, however, they are not adequate to prepare these students adequately into their communities. For instance, on the issue of how the curriculum has been structured to form an integral part essentially to meet their needs into the communities; the following were the responses stated:

"...You see this curriculum we have now as compared to the old one, is quite of good content, included the various skills needed to teach daily skills and home management for the students but the resources are so limited that we are compelled to ignore some of them and use our own means to teach them".

"...In actual fact, they need to provide the materials themselves but some cannot afford it others are due to the perception their parents have about their education".

"...I am a teacher for the vocational training aspect. I sometimes get so frustrated and wanting to quit teaching but my love for them wouldn't let me leave”.

"...Sir, for me I would say teaching in the special school is a curse and I regret doing that course in school".

\subsubsection{Adequacies of the classroom for training}

It came to light that classrooms are adequately available for them to undertake their activities.

"...With classrooms the center has no problem though not spacious we are able to manage”.

"...Though the workshop is said to be limited, the classroom is of a different issue. As you can see for yourself".

\subsubsection{Staff Adequacy at the Center}

The idea of the adequacy of staff is an issue most special schools and rehabilitation centers are battling with and the history varies from one school to the other depending on the location and conducive nature of the environment. (Avoke 2005) Consequently, its effect crucially follows the common trends of lack of skills for the intellectually disabled to live independently within their communities resulting in their abandoning unto the street. One of the teachers commented that:

"...Staff attrition is very high because of the nature of the work without any motivation. This has compelled me to employ those who are not qualified for the job"

“...Others also do not have a love for the job and mistreat the student, talking to them any whilst others either come to school late or habitually absent themselves".

"... All I will say is there is "nothing to write home about "considering the number of staff present at the center”.

\subsubsection{Recruitment of members of staff}

Connectively, the recruiting of staff is mainly through the appointment of the government for those who are qualified and appropriate to occupy the various positions. However, as my position as the headmaster of the center, I am sometimes mandated to appoint people who are willing and have volunteering spirit to work as casual workers but with hard 
work and commitment promotes the individual to become a permanent work after a while.

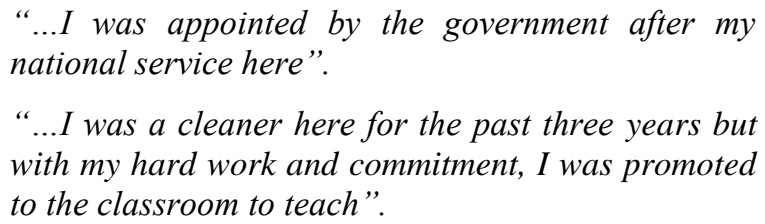

\subsubsection{Management Structure}

Like any other institution, management structure at the school could be stated that, relatively, there is an organogram with which the staff is ranked according to their competence and qualification. A clear definition of their roles and responsibilities are also spelled out to them to carry activities with weekly rotation to see to the day - to- day routine of activities at the center. This helps to propagate progress at the center for an effective program to take place.

3.5 Challenges Affecting the Effective Transition Programs for Students with Intellectual Disabilities in the Schools

The following were the responses from the respondents with respect to the challenges affecting the effective transition programs for students with intellectual disability'

\subsubsection{Graduation of students (Annually or Specific Period)}

On the issue of how often the trainees graduate either annually or have specific periods, the remarks were:

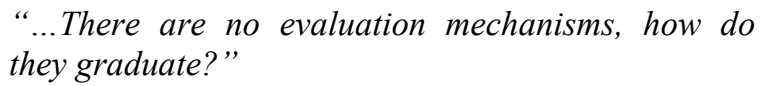
graduated from this center with this kind of training they are receiving from here, though not bad there are no structures and mechanisms in place to connect the community and other training institutions"

"...How I wish some of those who are moderate intellectually disabled could graduate because some of them have been in this center for a longer time but resources are not available and individuals are not willing to help".

\subsubsection{Parental Support for students with ID at the schools}

From the research, it was revealed that some of the parents or guardians of the students with ID are supportive and they always come to the schools from time to time to check up on their wards and provide them the necessary items. The teachers remarked that; it will surprise you to know that the parent wishes their children do not even vacate.

"...Sometimes we call for Parent Teacher Association (PTA) and only a few attend. So, we adopted a mechanism of calling them anytime there is a program and have to put across some" condition" such as paying some amount to deter them from indulging that act".

“...Some parents are responsible, just recently we had a parent donating toiletries, assorted drinks and bags of rice whiles others also abandon the children without any attention".

A senior housemother from one of the selected schools added that;

"...Some parents come with items when coming to school to visit their wards but on the contrary, not all parents visit their children on a regular basis and this sometimes make the students feel left out".

\subsubsection{Structured Policy in Place for Activities}

On whether there is the availability of policy for transition programs in the schools, the study found out that, special education in Ghana from immemorial lack governmental support and therefore has kept lip tight about services that are relevant to the upkeep of rehabilitation centers and special schools. It is also revealed that that, there are no clear-cut policies to carry out programs to meet the needs of these individuals

\subsubsection{Staff Motivation}

Indeed, the absence of motivation was acknowledged to have some influence on the students and the work of the staff. There were a majority of the respondents who had a bitter experience on this matter and commented as follows:

"...There is no motivation in teaching in a special school due to a lack of resources to teach practical programs in the curriculum content".

“...Few facilities exist at the center such as sewing machines, training workshops, carpenters' bench, and tools, tie and dye materials and others, available in the school",

The head teacher added that the salaries for we the staff are so small and cannot take care of our family; in another way, the grants for the upkeep of the center are delayed so much and some parents also fail to acknowledge what the teachers are doing for their wards.

\section{DISCUSSION OF RESULTS}

4.1 Availability of transition programs for students with intellectual disability in the schools

The study found out that programs such as arithmetic and mathematics, language literacy, and skills in home management, daily living skills and pre-vocational skills programs such as leatherwork, chalking making, candle making, doormat, tie and dye, art and painting, beads making, etc. are offered in both schools. However, according to Avoke et al. (1998), as cited in (Mantey 2017) states that such transition programs have already been in existence in Ghana since the era of the Castle schools, the missionaries introduced 
vocational trades in the elementary, secondary and tertiary schools. Moreover, it was revealed that such programs offered at the schools do no meet the needs of the students due to lack of inadequate resources. The absence of a policy on transition has affected the essence of transition programming for students with intellectual disabilities because the interview granted revealed that these programs are not structured well to meet the needs of these individuals. Consequently, Avoke (2004), in line with his research conducted, stated categorically that, these individuals do not basically see any relationship between the skills they learn in the school and their future lives and often affect their chances of getting jobs or engaging in their own self-work.

\subsection{How transition programs prepare the students for community integration}

There is no doubt that most people with disabilities, especially, the intellectually disabled spent most of their time in special schools. This, notwithstanding is a no different issue with those in Deduako Vocational Special School and Garden City Special School, where these individuals undergo various kinds of training in order to adjust themselves in their community after their training programs. It is evident in Ghana, that, the ultimate aim of training these individuals is to equip them with function-able skills to enable them to live independent lives.

However, the majority of these individuals according to Avoke (1998) become a burden unto their families due to the nature of the training they undergo. The study also revealed that students did not have diverse means of training as admitted by the teachers, they were good and function-able in their own field of work. It is important not to lose the sight of the fact that Article 23 of the United Nation Convention on the Rights of the Child recognizes the right of the child to enjoy a full and decent life, in conditions which ensures dignity, promote self- reliance, and facilitates the child's active participation in the community. Therefore, Lindqvist (1999) argues that these individuals have the same right as other children to participate in activities to foster their development; hence, nothing should be an obstacle to such participation.

\subsection{Resources available for effective transition programming in the schools}

The study found out most of the resources had deteriorated whiles others too were obsolete to serve their purpose and had since rendered the resources ineffective. This was attributed to inadequate financing from the government to the schools. Government funding must be directed appropriately towards schools concerned, providing sufficient vocational centers, basic tools, and equipment for training and other learning facilities (Disability Act 175, 2006).

Studies indicate that for effective transitional programs of students with intellectual disability to be achieved there needs to be adequate provision of resources. Sarbah and Gidiglo
(2003) stated that appropriate resources, training facilities, and vocational instructors should be made available in the training and development of students with intellectual disabilities. Smither (2002) also stressed that most schools for the intellectually disabled have been poorly equipped and neglected, with insufficient teaching-learning aids needed to produce quality students. Smither's continued that, the characteristics of good vocational education are not seen, and that individuals are mostly seen as less privileged and inappropriate graduates due to insufficient resources and this hinders most of the students with ID to integrate into their various community.

\subsection{Challenges affecting the effective transition programs for students with intellectual disabilities in the schools}

Persons with disabilities especially those with intellectual disabilities as stated by Avoke (1998) face different types of transition that should be successfully approached to ensure stable adulthood. However, there are different kinds of obstacles that come along with their transition periods. From the study conducted at Deduako Vocational Special School and Garden City Special School, the schools are far not different from the issue stated above. Addressing the needs of students with disabilities relatively varies from each other, however, due to the major challenge in running special schools such as Deduako Vocational School and Garden City School in the area of resources, resort to a limited area of training. Avoke (2004) cited Wehman(1996) these individuals need intensive skills in vocational training structured which form an integral part of their curricula for complete rehabilitation into their community. In addition to this, Clark, Carlson, Fisher, Cook, and D'alonzo (1991) made it clear that for transition programming to be successful, individuals need to be taken through guidance and counseling, personal care skills, home management training, occupational training and information on the awareness of job opportunities in the communities, expectations, and characteristics of the job and workers. Contrary to this, happen in many special schools such as Deduako where they are clinging to the old ways of training these individuals. Inline to this could be stated that maybe due to lack of commitment on the government to fully support the system through a progressive policy implemented to give it a mandate as the United State of America. This affects the impact of the programs on the lives of these individuals

\section{CONCLUSION AND RECOMMENDATION}

\subsection{Conclusion}

It should be noted that Article 23 of the United Nation Convention on the Rights of the Child recognizes the right of the child to enjoy a full and decent life, in conditions which ensures dignity, promotes self- reliance and facilitates the child's active participation in the community. Therefore, the intention of this study was to examine how to transition programming to promote the integration of students with intellectual disabilities into their various communities for 
independent living. The bottom line drawn is the absence of proper policy and legislation by government-mandated to provide effective monitory and evaluative mechanisms, structures necessary for proper procedures needed by all stakeholders to link up for the provision of transition programs These individuals need to enjoy equal rights as their other non-disabled counterparts.

\subsection{Recommendation}

Based on the findings and the prevailing circumstances, the following recommendations were made:

1. In order for these students to have full access to community services, preparation of programs should be geared towards meeting their needs, hence, much attention is needed by all stakeholders in the education sector to revise the content of their curriculum very well inculcating all the skills needed to develop. It is crucial for a parent to know that they are the central core for their children's development, therefore they should be obligated to take their roles and responsibilities seriously in providing, protecting and advocating for the right of their children to have access to services available to them.

2. Networking and linkages of all special schools and rehabilitation centers should be made across the country to put proper measures and mechanisms in place to facilitate the transition programming for successful community integration. Moreover, awareness-raising should be made to the general public to educate them on what they need to know about disability in order to be responsive to the needs of children with disabilities particularly the intellectually disables.

3. The government of Ghana should emulate what the United States has done by making a policy mandatory for all stakeholders to adhere to in formulating transition programming for these individuals to be effective. This will help the government to be obligated to the plight of these students by resourcing their schools with modern tools and equipment with releasing funds on time. In all more professionals should be trained with lucrative salaries to boost their interest in working.

\section{SUGGESTION FOR FURTHER RESEARCH}

There is a need for further research to be carried out on the government's commitment to the special school to promote the quality of transition programming for persons with disabilities across the country. This would bring improvement in transition programs through a collaboration of effort by all stakeholders concerned.

\section{REFERENCES}

[1] Abdullah, A., et al. (2018). "Barriers to childcare in Children's Homes in Ghana: Caregivers' solutions." Children and Youth Services Review 88: 450-456.

[2] Ametepee, L. K. and Anastasiou, D (2015). "Special and inclusive education in Ghana: Status and progress, challenges and implications." International Journal of Educational Development 41: 143-152.

[3] American Association on Intellectual and Developmental Disabilities (n.d.). Definition of Intellectual Disability. [Online] Available at aaidd.org/intellectual-disability/definition. [Accessed 18th December 2015]

[4] American Psychiatric Association (2013). Diagnostic and Statistical Manual of Mental Disorders (DSM-5®). American Psychiatric Pub.

[5] Avoke, S. (1998). Working together towards successful transition: School to adult life: Iowa Department of Education.

[6] Avoke, M. (2004). Introduction to special education for universities and colleges. Accra: City Publishers and salt and Light

[7] Avoke M.K. \&Avoke S.K. (2004). Inclusion rehabilitation and transition services in Special Education Winneba: Department of special education

[8] Avoke, M. (2005) Special Educational Needs in Ghana. Winneba: Department of Special Education. Basic for teachers: A handbook based on the free online learning course developed by Dyslexia International Disability and Society Journal (17)4 (revisit arrangement)

[9] Ballard, G. (1995). Career Placement for Learning Disabled Students. New York: Fashion Institute of Technology.

[10] Blackorby, J. \& Wagner, M. M. (1997).The Employment Outcomes of Youth with Learning Disabilities. Austin, TX: PROED, Inc.

[11] Learning Disabilities in Adulthood, edited by P. J. Gerber and H. B. Reiff, pp. 194- 203. Stoneham, MA: Butterworth-Heinemann.

[12] Biritwum, R. B., et al. (2016). "Prevalence of and factors associated with frailty and disability in older adults from China, Ghana, India, Mexico, Russia, and South Africa." Maturitas 91: 818

[13] Black, M. M. and Lawn, J.E. (2018). "Early childhood developmental disabilities - data still needed." The Lancet Global Health 6(10): e1050-e1051.

[14] Cadogan, K., et al. (2018). "S.M.A.R.T. Transitions: A Program Evaluation." Journal of Pediatric Health Care 32(4): e81-e90.

[15] Centre for Developmental Disability Health (2015). Understanding Developmental Disability. [Online] Available at www.cddh.monash.org/.../healthcare-and-people-with-intellectualdisabil... [Accessed 18th December 2015]

[16] Chakraborty, J. (2018). "Proximity to extremely hazardous substances for people with disabilities: A case study in Houston, Texas." Disability and Health Journal.

[17] Council for Exceptional Children (2001).Standards for the preparation of transition specialists. Arlington, VA: Author. ?? (Revisit)

[18] Clark, G. M., Carlson, B. C., Fisher, S., Cook, I. D., \& D'alonzo, B. J. (1991). Career development for students with disabilities in elementary schools: A position statement of the Division on Career Development. Career Development for Exceptional Individuals, 14(2), 109-120.

[19] Creswell, J.W. (2005). Educational research: Planning, conducting and evaluating quantitative and qualitative research. (2nd Edition). New Jersey: Merill Prentice Hall.

[20] Crosbie, S. and O'Sullivan, C. (2015). "Attitudes and beliefs of parents/careers of children with physical and intellectual disabilities in Western Ghana." Physiotherapy 101: e277-e278.

[21] Disabled World (2015). Cognitive Disability: Information on Intellectual Disabilities. [Online] Available from www.disabledworld.com/disability/types/cognitive/ [Accessed 18th December 2015

[22] Division on Career Development and Transition (2000).Transition specialist competencies (Fact sheet). Reston, VA: Author

[23] Emmel, N. (2013). Sampling and choosing cases in qualitative research: A realist approach: Sage.

[24] Essuman, A., et al. (2018). "Long-term Care for Older Adults in Africa: Whither Now?" Journal of the American Medical Directors Association 19(9): 728-730. 
[25] Gadagbui, G. (2010) Education in Ghana and special needs children: City Publishers, Accra.

[26] Haugh, B. (1993). The transition from school to adult life for pupils with disabilities: Best practices in planning and programming transition to adult life. New Jersey: Department of Education Office of Special Education Programmes.

[27] Hayford, S. K. (2000). Evaluation of vocational programs of special schools for children with mental retardation in Ghana. The University of Cape Coast unpublished master's (Retrieved: 5th May 2015) from thesis. http:www.vocation.org.educatel

[28] Howley, M. (2010). An investigation into an interactive program for children on the autism spectrum: outcomes for children, perceptions of schools and a model for training. Journal of Research in Special Education Needs, Jun, 10(2): 115.

[29] Intellectual Disability Rights Service (2009). About Intellectual Disability. [Online] Available from www.idrs.org.au/education/about-intellectual-disability.php [Accessed 18th December 2015]

[30] Karnes, M. \& Taska, J. (1975). Children's Responses to Intervention Programs. In J.J. Gallagher (Ed) The Application of Child Development Research to Exceptional Children. Reston, VA: Council for Exceptional Children.

[31] Katz, G. and Lazcano-Ponce, E. (2008). Intellectual Disability: Definition, Etiological Factors, Classification, Diagnosis, Treatment, and Prognosis. Salud pública de méxico, 50, pp.s132s141.

[32] Kiarie, M.W., (2005) Educational services for students with mental retardation in Kenya retrieved from http://files.eric.ed.gov/fulltext/EJ843605.pdf

[33] Kniel, A. (2007) Transition from school to work: A handbook for parents and teachers for handicapped adolescents in Ghana. Accra: salt and light.

[34] Landesman Ramey, S., \& Ramey, C. T. (1999). Early experience and early intervention for children" at risk" for developmental delay and mental retardation. Mental retardation and developmental disabilities research reviews.

[35] Lardon, A., et al. (2018). "Predictors of disability and absenteeism in workers with non-specific low back pain: A longitudinal 15month study." Applied Ergonomics 68: 176-185.

[36] Ministry of Education (2005) Statistical yearbooks of education in 2005(in Chinese).TaipeiMinistry of Education.

[37] Mirfin-Vietch, B. (2006). Education for Adults with an Intellectual Disability (Including Transition to Adulthood). Wellington: National Health Committee.

[38] Morris M. D. \& Levinson, J. K. (2005). Preparing students for the future world of work, NASSP Bulletin

[39] Olusanya, B. O., et al. (2018). "Developmental disabilities among children younger than 5 years in 195 countries and territories, 1990-2016: a systematic analysis for the Global Burden of Disease Study 2016." The Lancet Global Health 6(10): e1100e1121.

[40] Pearson,V. W. C \& Pierini, J (2004). The Structure and Comment of Social Inclusion. Journal of Disability and Society, 4th Vol 17( page 365)

[41] Pereira, N. S. and A. Marques-Pinto (2018). "Development of a social and emotional learning program using educational dance: A participatory approach aimed at middle school students." Studies in Educational Evaluation 59: 52-57.
[42] Przybylowicz, T. A. (2018). "Transitioning from Education to Practice: Associate Degree Program, Senior Clinical at a Skilled Nursing Facility, a Pilot Program." Teaching and Learning in Nursing 13(4): 240-243.

[43] Salzer, M.S. (2006). Introduction. In M.S. Salzer (ed.), Psychiatric Rehabilitation Skills in Practice: A CPRP Preparation and Skills Workbook. Columbia, MD.: the United States Psychiatric Rehabilitation Association.

[44] Sarbah, A., \& Gidiglo, G. (2003). Factors blocking transition from school to work for youths with intellectual disabilities: A case study at Echoing Hill village Ogbojo-Accra. Unpublished Long Essay. University of Education, Winneba.

[45] Shapiro, B. K., \& Batshaw, M. L. (2011). Intellectual disability. Nelson textbook of pediatrics. Philadelphia: Elsevier Saunders.

[46] Schalock, R. L., Gardner, J. F. and Bradley, V.J. (2007). Quality of Life for People with Intellectual and Other Developmental Disabilities: Applications across Individuals, Organizations, Communities, and Systems. American Association on Intellectual and Developmental Disabilities.

[47] Test, D. W., Mazzotti, V. L., Mustian, A. L., Fowler, C. H., Kortering, L., \& Kohler, P. (2009). Evidence-based secondary transition predictors for improving postschool outcomes for students with disabilities. Career Development for Exceptional Individuals, 32(3), 160-181.

[48] Trach, J., Oertle, K., \& Plotner, A. (2014). Transition from school through process to outcomes. Career development, employment and disability in rehabilitation: From theory to practice, 389-400.

[49] Vincent-Onabajo, G. O. and W. S. Malgwi (2015). "Attitude of physiotherapy students in Nigeria toward persons with disability." Disability and Health Journal 8(1): 102-108.

[50] Vlachos, C.J., (2008). Developing and managing vocational training and transition planning programme for intellectually disabled learners. Cardinia: University of South Africa, Department of Education Management.

[51] Wang, K.Y., (2006). Adults with intellectual disabilities live in institutions: Parent association for persons with intellectual disabilities. Newsletter 49. 12-22 [Retrieved on August 2014] http//www.acid2011korea.org/kaidd_abs/.../20110600449_18th_A -50.pd...

[52] Wehman, C. (2003). Person centered and collaborative supports for college success.Education and Training in Developmental Disabilities, 39, 67-73.

[53] Wehmeyer, M. L., Lattin, D. L., Lapp-Rincker, G., \& Agran, M. (2003). Access to the general curriculum of middle school students with mental retardation. Remedial and Special Education, 24(5), 262-273.

[54] Weisz, J. R., \& Yeates, K. O. (1981). Cognitive development in retarded and nonretarded persons: Piagetian tests of the similar structure hypothesis. Psychological Bulletin, 90(1), 153.

[55] World Health Organisation (2015). Mental Health- Definition: Intellectual Disability. [Online] Available from www.euro.who.int/.../health...health/.../definition-intellectualdisability. [Accessed 18th May, 2015]

[56] Zhang, D. \& Stecker, P. M. (2001). Student involvement in transition planning: Are we there yet? Education and Training in Mental Retardation and developmental disabilities, 36(3):293303. 